\section{Undergraduate antimicrobial stewardship training for pharmacy students: Creating a foundation for containment of antimicrobial resistance in South Africa}

To the Editor: The inappropriate and excessive use of antimicrobial agents has cultivated the development and progression of antimicrobial resistance worldwide, which has been recognised as a threat to global health and safety. ${ }^{[1]}$ In response to this alarming growth in antimicrobial resistance, antimicrobial stewardship initiatives, which aim to improve the judicious use of antimicrobial agents, have gained global support. ${ }^{[2]}$ The Antimicrobial Resistance Strategy Framework in South Africa (SA) recognises the education of healthcare professionals as a strategy for containment of antimicrobial resistance in $\mathrm{SA} .{ }^{[3]}$

Prescribers and pharmacists serve as the 'nucleus' of antimicrobial stewardship teams. ${ }^{[4]}$ Pharmacists play a crucial role in the surveillance of and feedback on antimicrobial stewardship practices when evaluating and dispensing prescriptions ${ }^{[5]}$ It is, therefore, essential that both medical and pharmacy students receive adequate undergraduate antimicrobial stewardship training, so as to ensure the effective implementation of antimicrobial stewardship in practice.

The guest editorial by Brink, Schoeman and Muttingh ${ }^{[6]}$ published in the May 2017 issue of the SAMJ correctly emphasised a current barrier to the implementation of antimicrobial stewardship in SA: a lack of undergraduate antimicrobial stewardship training for prescribers. The editorial commented on the results of an SA study that revealed the apparent gaps in the antimicrobial stewardship knowledge of participating final-year medical students. ${ }^{[7]}$

Similarly, a national survey was conducted in 2016 that focused on the knowledge and perceptions of antimicrobial stewardship concepts among final-year pharmacy students in SA. ${ }^{[8]}$ The results of the study revealed that although the majority (95.8\%) of students felt that the implementation of antimicrobial stewardship programmes is essential, only $71.9 \%$ were familiar with stewardship programmes in SA, and $96.5 \%$ of participants stated that they would like more education on antimicrobial stewardship. ${ }^{[8]}$

At the 37th annual general meeting of the Academy of Pharmaceutical Sciences of SA, held in July 2016, it was emphasised that steps need to be taken to ensure adequate undergraduate antimicrobial stewardship training for pharmacy students in SA. In response to the national call for undergraduate antimicrobial stewardship training for pharmacy students, a study is now being undertaken to develop a proposed minimum curriculum content suitable for implementation in undergraduate pharmacy degree programmes in SA. This study has the support of the SA National Department of Health.

The study aims to ensure that the proposed curriculum content is in line with international and national antimicrobial stewardship recommendations, while simultaneously incorporating the expertise of antimicrobial stewardship professionals in SA. The methodology involves a series of phases, including a desktop review; consultation with academic pharmacists from SA universities; and consultation with experts in the field of antimicrobial stewardship in SA (including infectious disease specialists, clinical microbiologists and antimicrobial stewardship pharmacists).

The results obtained from the study phases will be collated to develop a well-informed and practical curriculum, capable of ensuring that graduating pharmacists are well equipped to execute their antimicrobial stewardship roles. The researchers invite any interested persons to contact the author if they would like to be involved in the study.

\section{Y Khan, S-A Boschmans, J McCartney}

Department of Pharmacy, Faculty of Health Sciences, Nelson Mandela University, Port Elizabeth, South Africa

khanyasmine07@gmail.com

\section{R Coetzee}

School of Pharmacy, Faculty of Natural Science, University of the Western Cape, Bellville, South Africa

1. Barlett JG. A call to arms: The imperative for antimicrobial stewardship. Clin Infect Dis 2011;53(1):S4 S7. https:// doi.org/10.1093/cid/cir362

2. World Health Organization. WHO Global Strategy for Containment of Antimicrobial Resistance Geneva: WHO, 2001. http://www.who.int/drugresistance/WHO_Global_Strategy.htm/en/ (accessed 20 May 2017).

3. National Department of Health, South Africa. Antimicrobial resistance national strategy framework 2014 - 2024. Pretoria: Government Printer, 2014.

4. Mendelson M. Role of antibiotic stewardship in extending the age of modern medicine. S Afr Med 2015;105(5):414-419. https://doi.org/10.7196/SAMJ.9635

MacDougall C, Polk R. Antimicrobial stewardship programs in health care systems. Clin Microbio Rev 2005;18(4):638-656. https://doi.org/10.1128/cmr.18.4.638-656.2005

6. Brink A, Schoeman J, Muttingh G. Undergraduate antibiotic stewardship training: Are we leaving our future prescribers flapping in the wind? S Afr Med J 2017;107(5):357-358. https://doi.org/10.7196/ SAMJ.2017.v107i5.12496

7. Wasserman S, Potgieter S, Shoul E, et al. South African medical students' perceptions and knowledge about antibiotic resistance and appropriate prescribing: Are we providing adequate training to future prescribers? S Afr Med J 2017;107(5):405-410. https:///doi.org/10.7196/SAMJ.2017.v107i5.12370

8. Burger M, Fourie J, Loots D, et al. Knowledge and perceptions of antimicrobial stewardship concepts among final year pharmacy students in pharmacy schools across South Africa. S Afr J Infect Dis 2016;31(3):84-90. https://doi.org/10.1080/23120053.2016.1192808

S Afr Med J 2017;107(9):722. DOI:10.7196/SAMJ.2017.v107i9.12649 